\title{
Experiments and assessments of a 3-DOF haptic device for interactive operation
}

\author{
Huijun Li, Aiguo Song, Bowei Li, Baoguo Xu and Hong Zeng
}

\begin{abstract}
Haptic devices have been applied in interactive operation to perform contact tasks. To explore the haptic perception characteristics of typical push-pull and rotation operation, an experimental system was built by incorporating a three degrees of freedom (3-DOF) haptic device and the virtual environment. In this system, the haptic device is used to provide motion commands to control the avatar in the virtual environment and to exert haptic feedback on the human operator generated by three motors. In order to evaluate the main influential factors of interactive system based on haptic devices, ergonomic assessments are designed and experimentally implemented. Preliminary studies on the factors including restoring force, guidance force, speed of the virtual avatar, and the arm length have been conducted. The results are of great significance for the design of a haptic device and haptic interaction system by analyzing the specific requirements of ergonomics.
\end{abstract}

Keywords: Haptic device, Haptic feedback, Interactive operation, Ergonomics assessments

\section{Introduction}

The development of many applications of interactive operation requires flexible haptic master to perform contact tasks. These tasks include interaction with computer-aided design models, telerobotic surgery, micro/nano-manipulation, undersea salvage, and space telerobotic exploration and maintenance, decontamination, and decommissioning of chemical and nuclear facilities $[1,2]$.

The execution of these tasks by a human operator is affected by his/her level of perception of the interaction objects [3]. This perception can be enhanced by audio, visual, and haptic cues. While visual cues are certainly mandatory and audio cues beneficial at times, haptic cues can significantly improve the flow of information from the environment to the human operator for many tasks requiring dexterity [4]. Haptic devices are the most popular devices to provide haptic feedback in interactive manipulations. As a medium between environments and human users, haptic interfaces transmit and display haptic stimuli [5]. With precisely controlled forces and torques exerted on the manipulator's fingertips, hand, or arm, subtle sensations are able to be perceived, thus a high level of immersion is constructed. In the past

\footnotetext{
* Correspondence: inter_2018@163.com; lihuijun@seu.edu.cn

School of Instrument Science and Engineering, Southeast University, Nanjing 210096, China
}

decades, several types of haptic master devices featuring the feedback function have been proposed, some of which are commercially available devices and some are experimental prototypes [6, 7]. The PHANToM, which is the most commonly used haptic device, can generate force feedback along six degrees of freedom (6-DOF) motions using motors [8]. The Xitack IHP of Xitack SA, which has been proposed for virtual reality applications, has 4-DOF force feedback functions [9]. With the Dual ArmWork Platform (DAWP) at Argonne National Laboratory [10], one of the key improvements the Cobotic Hand Controller can provide to DAWP operation is the implementation of virtual surfaces, or virtual constraints on motion, as suggested by Faulring [11]. Such haptic devices can reproduce the constraints or guidance and can vastly simplify execution of a contact task. While guidance or constraints can be implemented in the existing system, an active haptic device allows for the reproduction of these guidance or constraints for the human operator and may reduce operator's fatigue while increasing efficiency by eliminating unneeded or wrong motions in workspace. Large improvements on existing devices can only be achieved by a proper match between the performance of the device and human haptic abilities. To find out how the users can complete the operation with a haptic device by 
creating synthetic haptic experiences, quantitative human studies should be carried out. To determine the nature of these approximations, or, in other words, to find out what we can get away with in creating synthetic haptic experiences, ergonomics studies are essential. Understanding of such influencing factors as the guidance force, the reset force, the speed of the virtual avatar, and the arm length is critical for proper design specification of the hardware and software of haptic interfaces.

Current trend in design of haptic masters is to meet the need for designs with safety, high performance, sufficient workspace, enough force and torque, high stiffness, and small inertia [12-14]. By their nature, haptic devices operate in contact with a human operator. Greater research effort on the operator's perception and overall performance using the haptic devices could accelerate the development of haptic interaction technology [15-17]. In these researches, the haptic perception of the users was optimized and evaluated using haptic devices. Human factors as well as others that affect the design specifications of force-reflecting haptic interfaces were also of a concern [18].

In this paper, we introduced a novel three degrees of freedom (3-DOF) haptic device. Concerned with quantitative measures of influencing factors that affect the overall performance, the design specifications of haptic interaction system are presented. The remainder of the paper is organized as follows. Mechanical design and kinematical analysis of the haptic device are presented in Section 2. Construction of a haptic interaction system based on the proposed haptic device is presented in Section 3. Experimental method and construction are presented in Section 4, and the performance of the proposed system is verified experimentally in Section 5 . The paper is then concluded in Section 6.

\section{Three DOF haptic device}

\subsection{Mechanical design}

Mechanical design of haptic devices is to meet the need for designs with sufficient workspace, enough force and torque, high stiffness, small inertia, and mechanical decoupling. However, some of these requirements, such as large stiffness and small inertia, are conflicting in nature $[19,20]$. Due to the multi-criteria and multi-domain functional and performance requirements of high-performing haptic devices, it is not sufficient to develop such a device by sub-optimizing the requirements from each separate discipline. The main design objectives of our device are to obtain a large workspace and mechanical decoupling and, at the same time, provide enough torque feedback. A parallel haptic device for interactive operation is designed which mainly consists of three mutually orthogonal translational axes that have lower inertia and better stiffness. The assembly drawing of this device is presented in Fig. 1.

The haptic device mainly consists of the base, the cuboid frame and cylindrical sleeve, the handle, three actuators, and photoelectric encoders. The proposed structure is similar to a three-axis gyroscope in which three axes are orthogonal and intersect at a fixed point (coordinate origin). The cuboid frame is mounted horizontally on the base and can be rotated around the $X$-axis. The cylindrical sleeve is mounted vertically to be rotated around the $Y$-axis. The handle is mounted coaxial with the $Z$-axis actuator in the cylindrical sleeve and can be rotated around the $Z$-axis. In this way, each kinematic freedom is independent and there is no motion interference which means kinematic coupling is mechanically avoided.

While haptic devices usually work at a low speed and provide high torque, corresponding reducers are equipped to increase the output torque and to reduce the rotational speed. Three DC motors manufactured by Maxon Corporation are used to generate the force/ torque feedback. The device is capable of rendering continuous forces up to $25 \mathrm{~N}$ in the $X$ - and $Y$-axes and torque of $0.5 \mathrm{Nm}$ around the $Z$-axis.

\subsection{Kinematics analysis}

The kinematic diagram of the designed haptic device is described in Fig. 2. The motion of the haptic device to any point in the workspace can be decomposed into

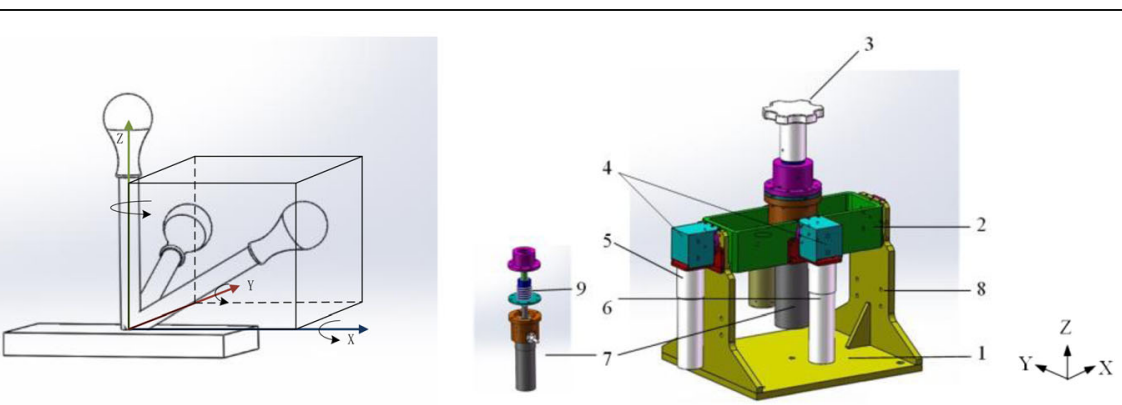

Fig. 1 Assembly drawing of the haptic device. (1) Base. (2) Cuboid frame. (3) Handle. (4) Bevel gears. (5) Y-axis actuator. (6) X-axis actuator. (7) Cylinder sleeve with Z-axis actuator. (8) Mounting holes for restoring rubber bands. (9) Restoring torsion spring 


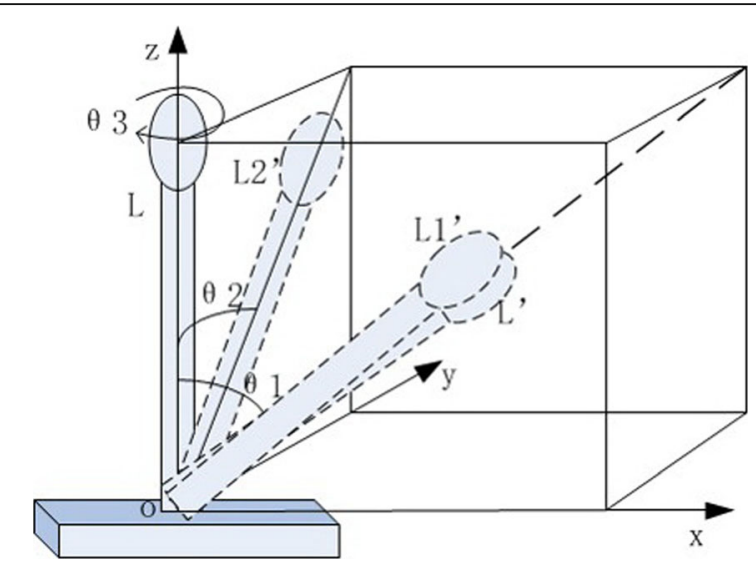

Fig. 2 Kinematical diagram of the designed haptic device

motion components on $x-o-z$ plane and $y-o-z$ plane respectively.

Assuming that the length of the handle bar is $l$ (from the intersection point to the end of the handle), the rotation angle around the $\mathrm{Z}$-axis is $\theta_{3}$, and the rotation angles on the $x-o-z$ plane and $y-o-z$ plane are $\theta_{1}$ and $\theta_{2}$ respectively, the coordinate of the end of the handle is $P$ $(P x, P y, P z)$, then the relationship between the coordinate of the end $P$, the length of the handle bar $l$, and the rotation angles of the handle is (ignoring minor deformation of the bar),

$$
\begin{aligned}
& P_{x}=\frac{l \times \tan \theta_{1}}{\sqrt{1+\left(\tan \theta_{1}\right)^{2}+\left(\tan \theta_{2}\right)^{2}}} \\
& P_{y}=\frac{l \times \tan \theta_{2}}{\sqrt{1+\left(\tan \theta_{1}\right)^{2}+\left(\tan \theta_{2}\right)^{2}}} \\
& P_{z}=\frac{l}{\sqrt{1+\left(\tan \theta_{1}\right)^{2}+\left(\tan \theta_{2}\right)^{2}}} \\
& \theta_{3}=\theta_{3}
\end{aligned}
$$

The rotational ranges of the haptic device about the $X-, Y-, Z$-axes are designed as $-60^{\circ} \sim 60^{\circ},-60^{\circ} \sim 60^{\circ}$, and $-90^{\circ} \sim 90^{\circ}$ respectively and the distance from the center of rotation to the end of the handle is $150 \mathrm{~mm}$, so the motion space of the haptic device can be deduced to be a spherical surface from formula (1-3) and its workspace is up to $259.72 \mathrm{~mm} \times 259.72 \mathrm{~mm} \times 93.30 \mathrm{~mm}$, as is drawn in Matlab as Fig. 3.

\section{Method and construction}

\subsection{Force-feedback system based on a haptic device}

The system consists of the human operator, the haptic device, the virtual environment which integrates with the graphical refresh model, the sampler, the virtual controller,

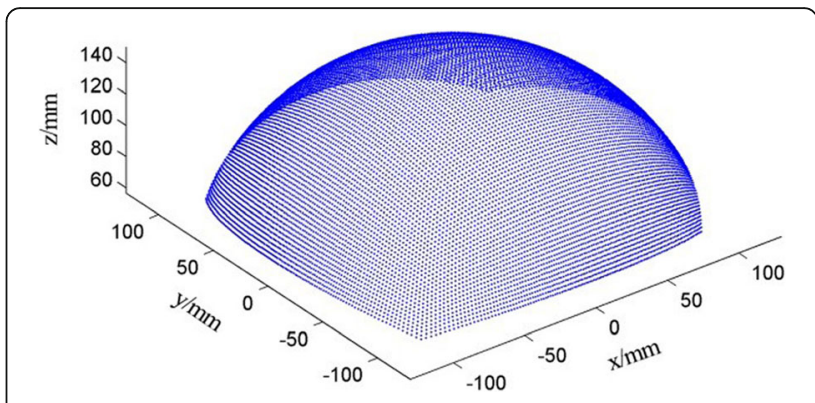

Fig. 3 Working space of the developed haptic device

the force rendering module, and the motion capture/force output model. Figure 4 shows the schematic diagram of the system. In this system, the haptic device is utilized to acquire the motion of the operator's hand to control the avatar in VR (virtual reality) and to provide force feedback to the operator so that he/she can feel the interactive force between the avatar and the virtual objects. The virtual environment is used to create a digital model of the physical world in the computer. The goal of force rendering is to calculate the virtual force based on the kinematics and dynamics model of different tasks and to convert the calculated virtual forces to match the capabilities with the haptic device for stable force feedback. The motion capture and force output model is to acquire the motion command $\left(x_{m}\right)$ and output the virtual force $\left(f_{v}\right)$ when a human operator operates the haptic device. The virtual controller is to program and control the avatar according to a predefined algorithm. The sampler model is to sample the pose of the avatar and the virtual objects, and the graphical refresh model is to renew the geometric model of the virtual environment which is shown to the human operator.

One of the major goals in this system is to provide the operator with force and visual feedback. The graphic model maintains the information about the geometric states of the avatar and the environment. Collision detection is conducted while performing tasks in the virtual

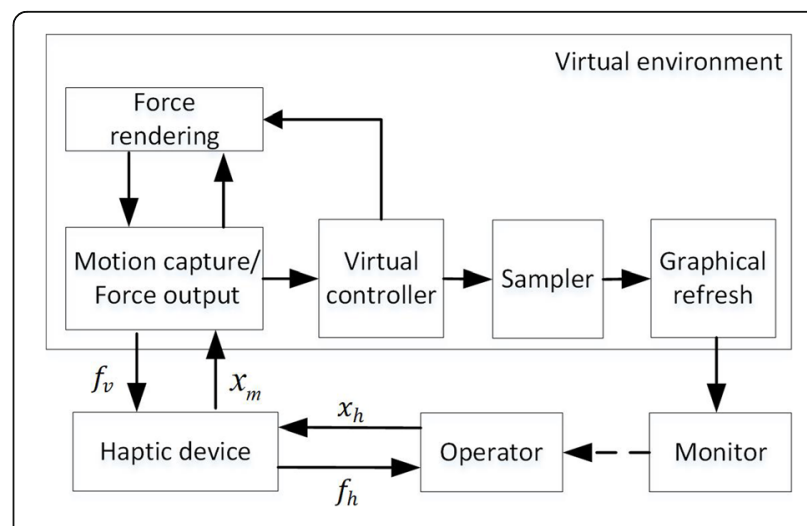

Fig. 4 Schematic diagram of the VR-based haptic interaction system 
environment. This allows the virtual objects to deform and give counterforce to the avatar. This force generated in the virtual environment exerts on the operator at the same time. Then the operator holding the haptic device feels the counterforce acting on the avatar and watches the motion of the virtual objects on the screen. The combination of visual and force feedback makes the operator feel the interaction of the virtual objects.

In order to improve the frequency of force feedback, the virtual environment module is divided into two loops, one is for visual display and the other is for force feedback. Since the two loops can be processed independently, the virtual force can be rendered at a high frequency of $500 \sim 1 \mathrm{kHz}$ to ensure the continuity and stable perception for the human operator. The graphics refresh loop is to complete the collision detection and the collision response (including deformation calculation and graphics rendering) at a lower frequency of tens of hertz.

\subsection{Software design}

The whole software is developed in Microsoft Visual Studio2008 platform, based on MFC (Microsoft Foundation Class) framework and Measurement Studio. OpenGL (Open Graphics Library) is used as a graphical interface to render the 3D virtual scene and to complete the dynamic element loading. The overall flowchart of the software is shown in Fig. 5.

There are several different functional areas in the software interface. According to the function of each module of the force feedback system, the layout of the whole software is designed in detail. The first is the serial mode setting area. Before opening the serial port, the operator needs to set the serial port parameters by pulling down the menu on the serial port baud rate and serial number to choose to improve the software versatility and compatibility. The second is data storage area which includes the rotation angles about each axis, the location and speed of the virtual avatar, and the feedback force information of

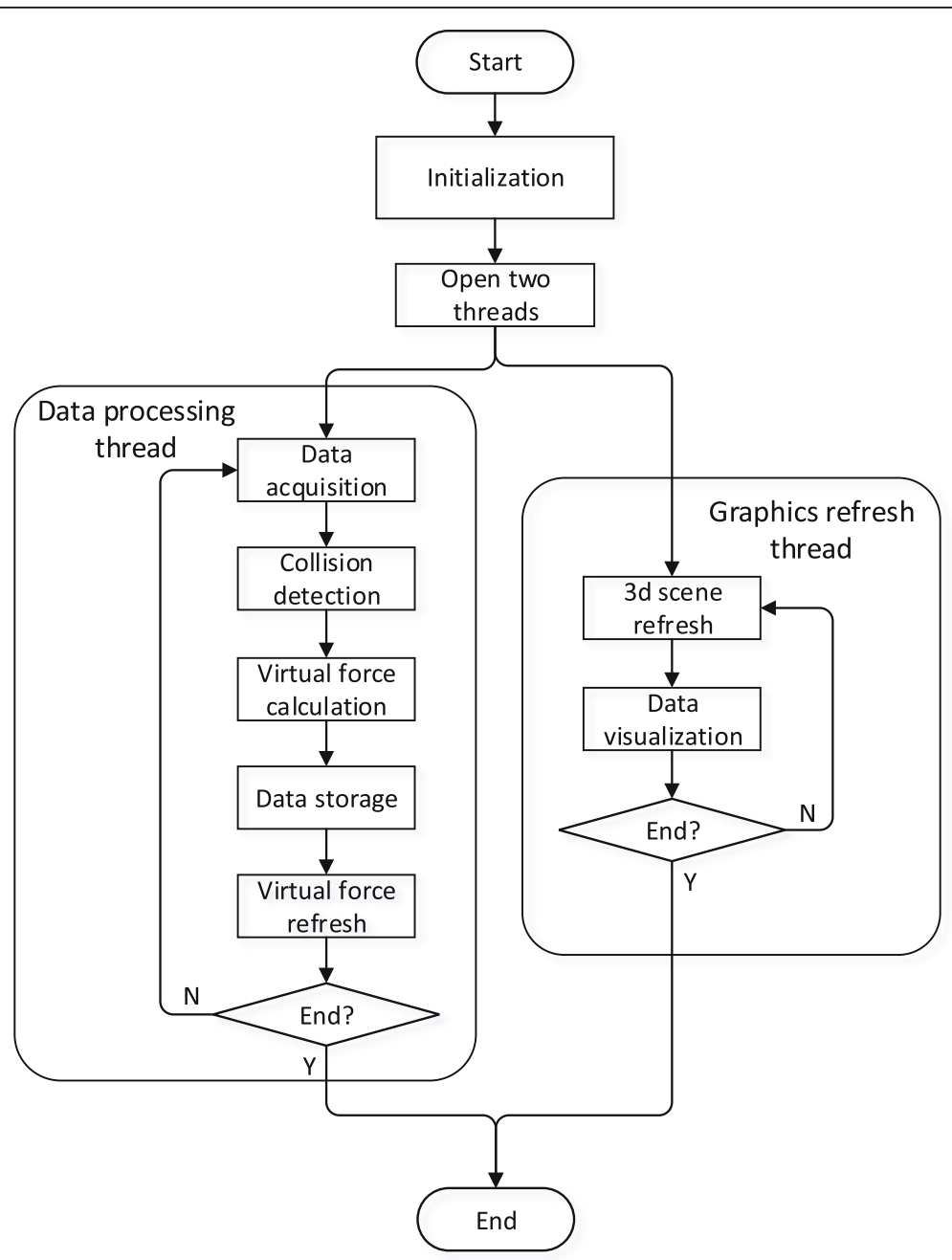

Fig. 5 Flow chart of the software for haptic interaction 


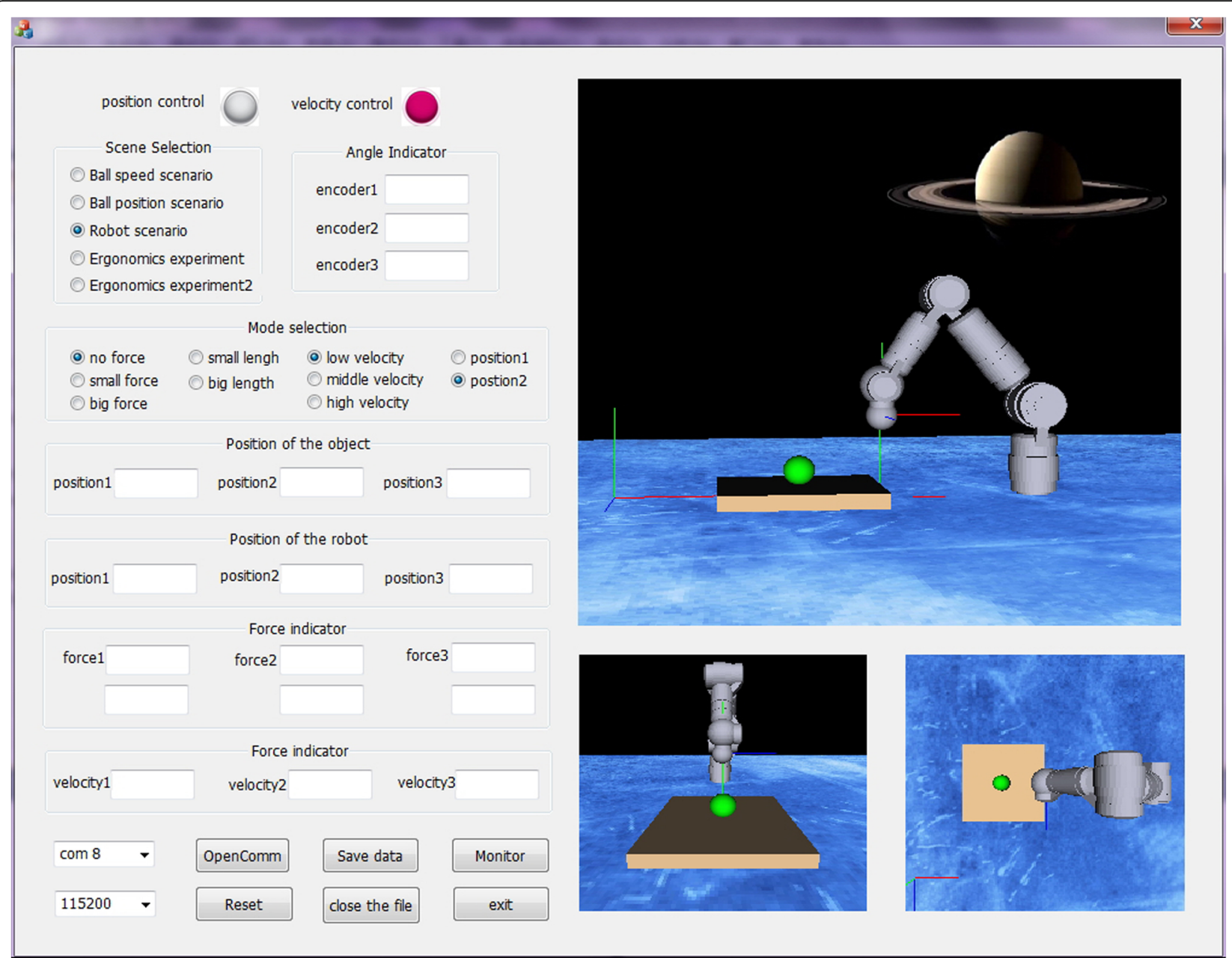

Fig. 6 Software interface of the force feedback system

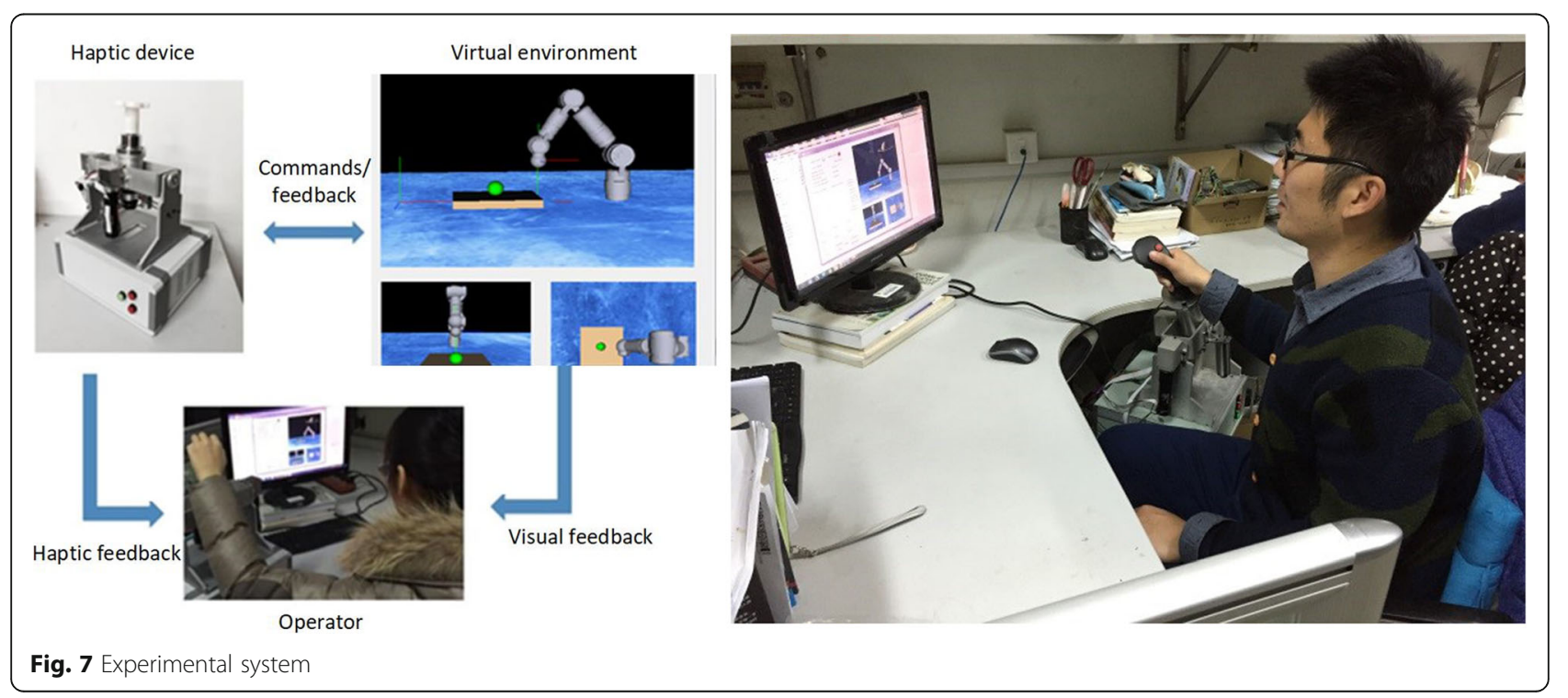



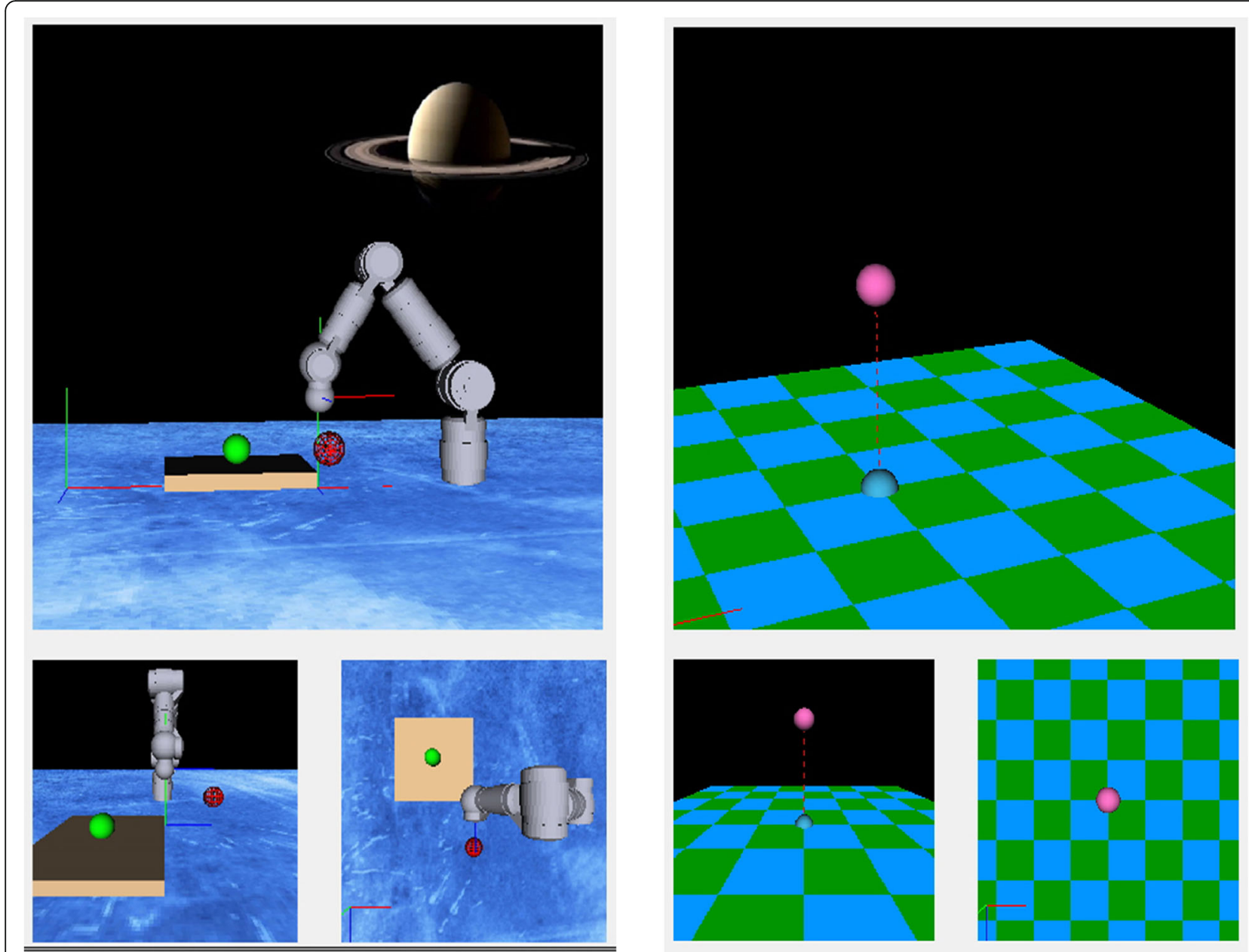

Fig. 8 Experimental tasks. a Virtual robotic scenario. b Ball tracking scenario

each degree of freedom. The third is data visualization area. In order to understand the feedback information in real time intuitively, the operator can click the monitor button to pop up a new window to display the three degrees of freedom and virtual force feedback in dials and waveforms. The fourth is virtual scene selection area. Three different virtual environments are designed in the software, namely the flexible ball scene model, virtual robotic task scene, and ball tracking scene. The operator can switch according to their own needs to operate in the

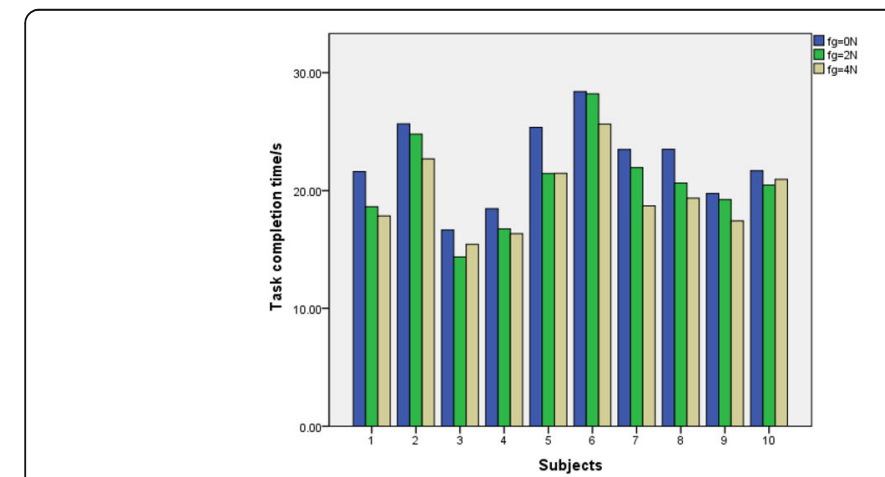

a

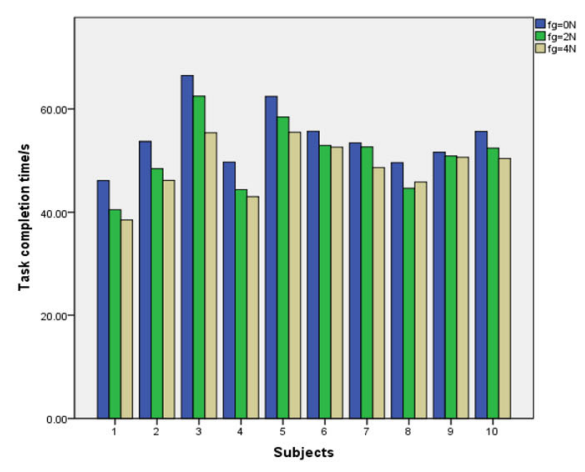

b

Fig. 9 Task completion time histogram in two different scenarios. a Virtual robotic scenario. b Ball tracking scenario 
Table 1 Average Task Completion Time (Second)

\begin{tabular}{llllllll}
\hline Subjects & \multicolumn{3}{l}{ Virtual robotic scenario } & & \multicolumn{3}{c}{ Ball tracking scenario } \\
\cline { 2 - 3 } & $f_{g}=0 \mathrm{~N}$ & $f_{g}=2 \mathrm{~N}$ & $f_{g}=4 \mathrm{~N}$ & & $f_{g}=0 \mathrm{~N}$ & $f_{g}=2 \mathrm{~N}$ & $f_{g}=4 \mathrm{~N}$ \\
\hline 1 & 21.625 & 18.633 & 17.846 & 46.157 & 40.492 & 38.491 \\
2 & 25.648 & 24.765 & 22.694 & 53.719 & 48.468 & 46.189 \\
3 & 16.654 & 14.369 & 15.432 & 66.492 & 62.483 & 55.371 \\
4 & 18.462 & 16.751 & 16.345 & 49.755 & 44.392 & 43.034 \\
5 & 25.349 & 21.459 & 21.469 & 62.449 & 58.428 & 55.482 \\
6 & 28.394 & 28.200 & 25.624 & 55.664 & 52.983 & 52.648 \\
7 & 23.462 & 21.954 & 18.694 & 53.469 & 52.694 & 48.691 \\
8 & 23.489 & 20.645 & 19.369 & 49.648 & 44.669 & 45.893 \\
9 & 19.762 & 19.239 & 17.425 & 51.673 & 50.945 & 50.694 \\
10 & 21.694 & 20.469 & 20.964 & 55.644 & 52.469 & 50.442 \\
\hline
\end{tabular}

corresponding scenario. The last is operation mode selection area. The haptic device can be used for position control or speed control. The operator can quickly switch between the position control mode and the speed control mode in this area. The overall software interface is shown in Fig. 6.

\section{Experimental results and discussion}

\subsection{Experimental system}

The haptic device is mainly used in the field of VR-based interaction to acquire the motion of the operator's hand and to provide the operator with force feedback. As a man-machine interface, not only mechanical but also ergonomic characters are important. Parameters of the haptic device such as the restoration force, the operating speed, and the guidance force will directly affect the comfort and efficiency, so understanding of the operator's operating habits is necessary to design a haptic device that is efficient, comfortable, and in line with people's operating habits. In order to experimentally evaluate the influence of the design parameters, we built a prototype of VR-based haptic interaction system. Several ergonomic experiments are designed and performed. Effective data collected is utilized to statistically analyze the characteristics and efficiency while operating with the developed haptic device.

The experimental system consists of the developed haptic device, the virtual environment, and the operator, as shown in Fig. 7. The operator can control the avatar and sense the force feedback of the virtual environment,

Table 2 Analysis of variance the maximum operating angle in six movement directions

\begin{tabular}{|c|c|c|c|c|c|}
\hline & Sum of the squares & df & Mean square & $F$ & Significance \\
\hline \multicolumn{6}{|l|}{$X+\left({ }^{\circ}\right)$} \\
\hline Inter-group & 279.912 & 2 & 139.956 & 4.651 & 0.018 \\
\hline Intra-group & 812.525 & 27 & 30.094 & & \\
\hline Sum & 1092.437 & 29 & & & \\
\hline \multicolumn{6}{|l|}{$X-\left({ }^{\circ}\right)$} \\
\hline Inter-group & 526.287 & 2 & 263.144 & 6.465 & 0.005 \\
\hline Intra-group & 1099.021 & 27 & 40.704 & & \\
\hline Sum & 1625.308 & 29 & & & \\
\hline \multicolumn{6}{|l|}{$\mathrm{Y}+\left(^{\circ}\right)$} \\
\hline Inter-group & 473.750 & 2 & 236.875 & 10.219 & 0.000 \\
\hline Intra-group & 625.872 & 27 & 23.180 & & \\
\hline Sum & 1099.622 & 29 & & & \\
\hline \multicolumn{6}{|l|}{$Y-\left(^{\circ}\right)$} \\
\hline Inter-group & 836.978 & 2 & 418.489 & 5.376 & 0.011 \\
\hline Intra-group & 2101.904 & 27 & 77.848 & & \\
\hline Sum & 2938.882 & 29 & & & \\
\hline \multicolumn{6}{|l|}{$Z+\left(^{\circ}\right)$} \\
\hline Inter-group & 1769.057 & 2 & 884.528 & 6.194 & 0.006 \\
\hline Intra-group & 3855.782 & 27 & 142.807 & & \\
\hline Sum & 5624.839 & 29 & & & \\
\hline \multicolumn{6}{|l|}{ Z- $\left(^{\circ}\right)$} \\
\hline Inter-group & 1160.788 & 2 & 580.394 & 2.300 & 0.120 \\
\hline Intra-group & 6814.036 & 27 & 252.372 & & \\
\hline Sum & 7974.824 & 29 & & & \\
\hline
\end{tabular}

$\mathrm{X}+$ means the positive direction of $X$-axis, $\mathrm{X}$ - means the negative direction of $\mathrm{X}$-axis. The rest in the same way 
such as contact force, frictional force, and guidance force, through the haptic device.

\subsection{Experimental tasks}

In this study, we mainly analyze several factors which play a significant role in the haptic interaction system, including the guidance force, the restoration force, the operating speed, and the arm length. Ten healthy volunteers aged 20-30 years (habitual use of the right hand) participated in the experiments. The experiments consist of two parts. The first part is the virtual robotic task scenario shown as Fig. 8a which is designed to test the typical operation of grasping and releasing. In this task scenario, the operator should control the virtual arm through the haptic device to grasp the green ball on the yellow plane, then move it to the red ball and release. Catching or releasing the ball is switched by the button on the handle of the haptic device. In this experiment, no guidance is provided and the operator should plan their own path according to the information available. The second part is a ball tracking scenario shown in Fig. 9b which is designed to test the typical operation of trajectory tracking. This is a path-guided operational task. The operator should control the blue ball through the haptic device to track the pink ball following the preset path. Once the blue ball touched the pink ball, the latter moved to the next positon and the operator should go on tracking. The entire process consists of six such cycles.

A variable-controlling approach is applied in the experiment to analyze the effects of each factor on the interactive operation. The first factor is the guidance force $\left(f_{g}\right)$ provided by the motors to guide the operator to move toward the target. Suppose the guidance force
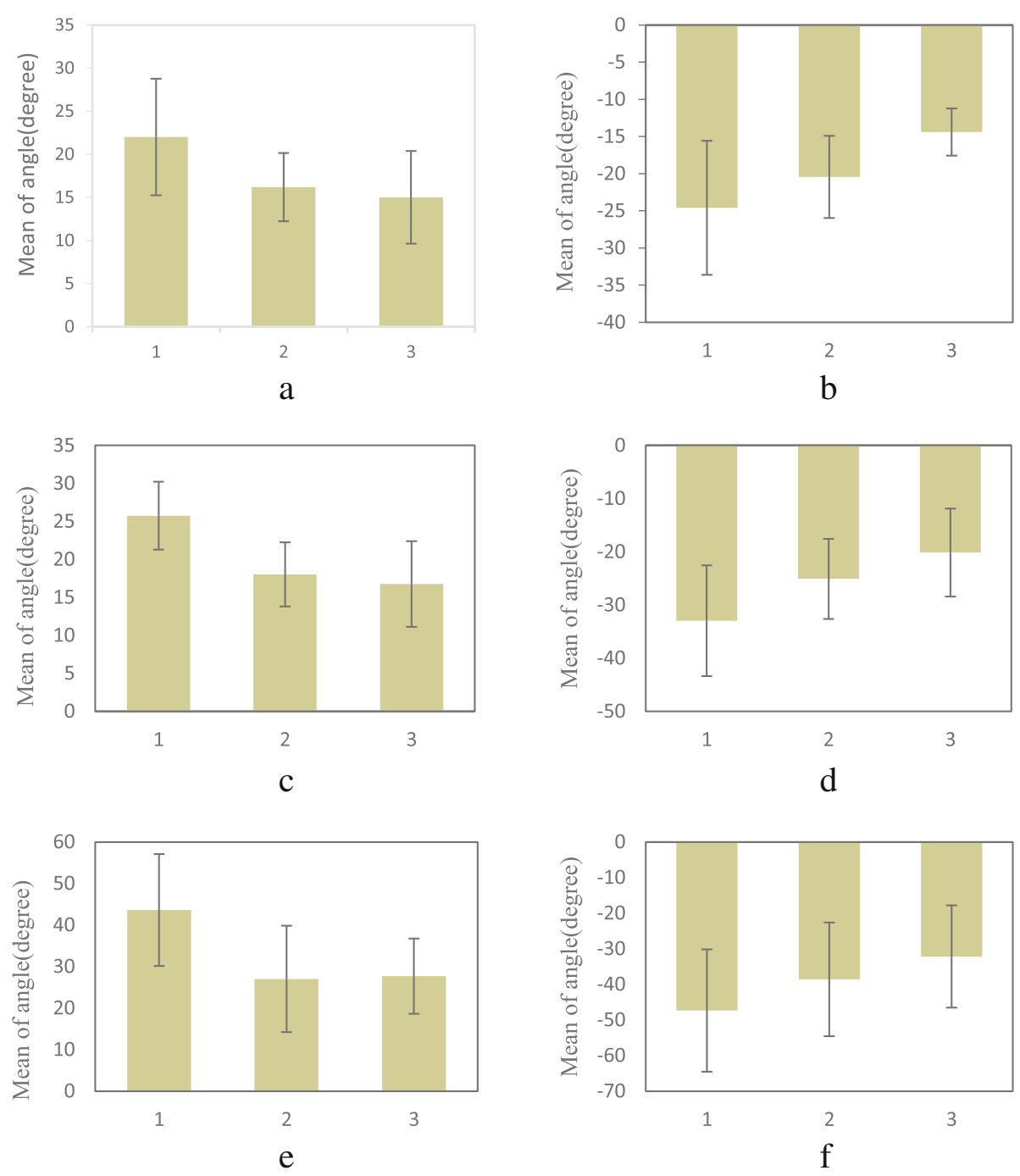

Fig. 10 Bar charts of the range of motion with three grades of restoring force $(95 \% \mathrm{Cl})$. a In the $X$-axis positive direction. $\mathbf{b}$ In the $X$-axis negative direction. $\mathbf{c}$ In the $Y$-axis positive direction. $\mathbf{d}$ In the $Y$-axis negative direction. e In the Z-axis positive direction. $\mathbf{f}$ In the Z-axis negative direction 

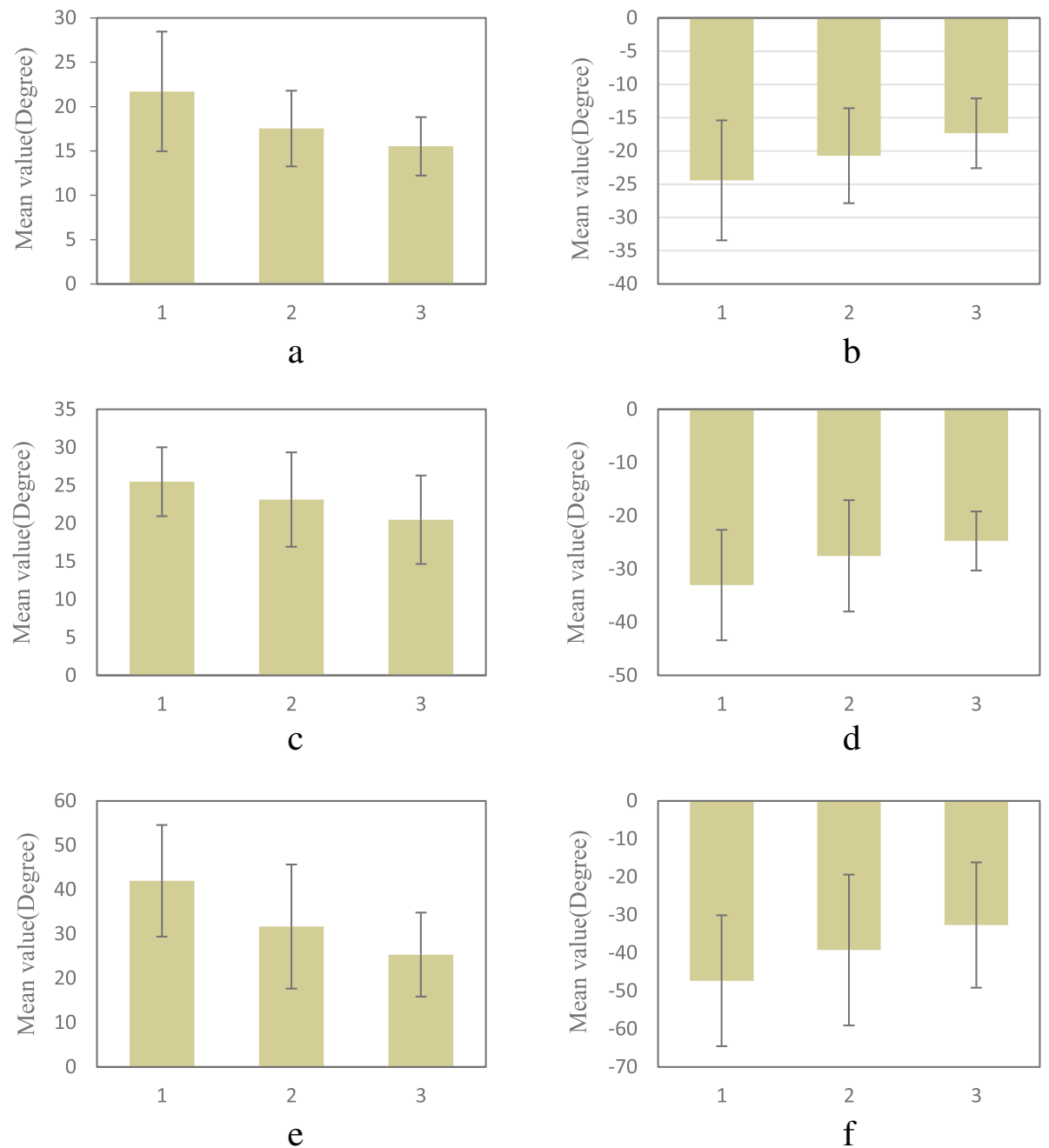

Fig. 11 Bar graph of the operating range in six motion directions with three grades of avatar speed. a X+. b X-. c Y+. $\mathbf{d} Y-$. e $Z+$. $\mathbf{f} Z-$

of $0 \mathrm{~N}, 2 \mathrm{~N}$, and $4 \mathrm{~N}$ is for conditions a1, a2, and a3 respectively. The second factor is the restoration force $\left(f_{r}\right)$ exerted by the motors which drives the haptic device back to the originating pose after operating or in the non-operating state. Suppose the restoration force of $0 \mathrm{~N}, 2 \mathrm{~N}$, and $4 \mathrm{~N}$ is for conditions b1, b2, and b3 respectively. The third is the speed of the virtual avatar which is set at $0.5 \mathrm{~cm} / \mathrm{s}, 1.5 \mathrm{~cm} / \mathrm{s}$, and $2.5 \mathrm{~cm} / \mathrm{s}$ for conditions $\mathrm{c} 1, \mathrm{c} 2$, and $\mathrm{c} 3$ respectively.

Among all these control factors, a1, b1, and c2 are the default control factors. During the experiments, when the influence of a variable is studied, the control factor of this variable is changed, and other variables are the default factors. For example, three groups of experiments under conditions of $\mathrm{a} 1 \times \mathrm{b} 1 \times$ $\mathrm{c} 2$, $\mathrm{a} 2 \times \mathrm{b} 1 \times \mathrm{c} 2$, and $\mathrm{a} 3 \times \mathrm{b} 1 \times \mathrm{c} 2$ should be carried out to study the effect of the guidance force in the virtual robotic scenario and the ball tracking scenario respectively. So each subject needs to do 18 experiments, and the experimental sequences of each subject were randomly arranged.

\section{Results and analysis}

\subsection{Effects of the guidance force}

In order to investigate the influence of the guidance force on the operation efficiency of the interactive system, three levels of $0 \mathrm{~N}, 2 \mathrm{~N}$, and $4 \mathrm{~N}$ were applied in the experiment. The average time for completing the designed task was recorded, as is shown in Table 1.

According to the statistical data in Table 1, a task completion time histogram of each operator with three levels of guidance force in two scenarios is shown in Fig. 9.

As can be seen from Fig. 9, the overall distribution of task completion time in three cases is consistent although the task completion time of ten subjects is slightly different. The guidance force will shorten the task completion time in both two scenarios. In the 
Table 3 Variance analysis of virtual avatar motion

\begin{tabular}{|c|c|c|c|c|c|}
\hline & Sum of the squares & $d f$ & Mean square & $F$ & Significance \\
\hline \multicolumn{6}{|l|}{$X+\left(^{\circ}\right)$} \\
\hline Inter-group & 199.247 & 2 & 99.624 & 4.004 & 0.030 \\
\hline Intra-group & 671.833 & 27 & 24.883 & & \\
\hline Sum & 871.080 & 29 & & & \\
\hline \multicolumn{6}{|l|}{$X-\left(^{\circ}\right)$} \\
\hline Inter-group & 250.083 & 2 & 125.041 & 2.350 & 0.115 \\
\hline Intra-group & 1436.942 & 27 & 53.220 & & \\
\hline Sum & 1687.025 & 29 & & & \\
\hline \multicolumn{6}{|l|}{$Y+\left({ }^{\circ}\right)$} \\
\hline Inter-group & 124.523 & 2 & 62.261 & 2.013 & 0.153 \\
\hline Intra-group & 835.071 & 27 & 30.929 & & \\
\hline Sum & 959.593 & 29 & & & \\
\hline \multicolumn{6}{|l|}{$Y-\left({ }^{\circ}\right)$} \\
\hline Inter-group & 354.916 & 2 & 177.458 & 2.142 & 0.137 \\
\hline Intra-group & 2236.635 & 27 & 82.838 & & \\
\hline Sum & 2591.551 & 29 & & & \\
\hline \multicolumn{6}{|l|}{$Z+\left(^{\circ}\right)$} \\
\hline Inter-group & 1412.462 & 2 & 706.231 & 4.761 & 0.017 \\
\hline Intra-group & 4005.187 & 27 & 148.340 & & \\
\hline Sum & 5417.648 & 29 & & & \\
\hline \multicolumn{6}{|l|}{$Z-\left(^{\circ}\right)$} \\
\hline Inter-group & 1083.262 & 2 & 541.631 & 1.721 & 0.198 \\
\hline Intra-group & 8496.079 & 27 & 314.670 & & \\
\hline Sum & 9579.341 & 29 & & & \\
\hline
\end{tabular}

case of the virtual robot scenario, task completion time was reduced by $15.3 \%$ at most and $8 \%$ on average with $2 \mathrm{~N}$ guidance force compared with no guidance force. When $4 \mathrm{~N}$ guidance force was available, task completion time was shortened by $20.3 \%$ at most and $12.7 \%$ on average. In the ball tracking scenario, task completion time reduction was $10.77 \%$ at most and $6.7 \%$ on average with $2 \mathrm{~N}$ guidance force compared with no guidance force. When $4 \mathrm{~N}$ guide

Table 4 Homogeneous test of variance under conditions of different avatar speeds

\begin{tabular}{lllll}
\hline & Levene statistic $\left(^{\circ}\right)$ & $\mathrm{df1}$ & $\mathrm{df2}$ & Significance \\
\hline $\mathrm{X}_{+}$ & 1.019 & 2 & 27 & 0.375 \\
$\mathrm{X}_{-}$ & 1.806 & 2 & 27 & 0.184 \\
$\mathrm{Y}_{+}$ & 0.985 & 2 & 27 & 0.386 \\
$\mathrm{Y}_{-}$ & 2.259 & 2 & 27 & 0.124 \\
$Z_{+}$ & 0.495 & 2 & 27 & 0.615 \\
$Z_{-}$ & 0.371 & 2 & 27 & 0.694 \\
\hline
\end{tabular}

force was available, task completion time was shortened by $16.60 \%$ at most and $10.6 \%$ on average. The result indicates that the guidance force can give the operator helpful hint to improve the operation efficiency and to shorten the task completion time. Although task completion time is averagely shortened with $4 \mathrm{~N}$ guide force compared with $2 \mathrm{~N}$ guide force, further experiments should be carried out to study the optimal guidance force for different subjects and different tasks.

\subsection{Relationship between the restoration force and the operating range}

To study the effect of the restoration force on the haptic interactive operation, the restoration force was set at three grades that include elastic force of the rubber bands only, elastic force plus $2 \mathrm{~N}$ motor output, and elastic force plus $4 \mathrm{~N}$ motor output. Other variables were the default factor. Univariate analysis of variance was used to analyze. Table 2 shows the result of variance analysis of the 
Table $\mathbf{5}$ LSD multiple comparison results of experimental data of virtual object velocity

\begin{tabular}{|c|c|c|c|c|c|c|c|}
\hline \multirow[t]{2}{*}{ Dependent variable } & \multirow[t]{2}{*}{ (I) $a$} & \multirow[t]{2}{*}{ (ノ) $a$} & \multirow{2}{*}{$\begin{array}{l}\text { Mean difference } \\
(I-S)\end{array}$} & \multirow[t]{2}{*}{ Standard error } & \multirow[t]{2}{*}{ Significance } & \multicolumn{2}{|c|}{ 95\% confidence intervals (Cls) } \\
\hline & & & & & & Lower limit & Upper limit \\
\hline \multirow[t]{6}{*}{$X+\left(^{\circ}\right)$} & \multirow[t]{2}{*}{1.00} & 2.00 & 4.17500 & 2.23082 & 0.072 & -.4023 & 8.7523 \\
\hline & & 3.00 & 6.18800 & 2.23082 & 0.010 & 1.6107 & 10.7653 \\
\hline & \multirow[t]{2}{*}{2.00} & 1.00 & -4.17500 & 2.23082 & 0.072 & -8.7523 & .4023 \\
\hline & & 3.00 & 2.01300 & 2.23082 & 0.375 & -2.5643 & 6.5903 \\
\hline & \multirow[t]{2}{*}{3.00} & 1.00 & -6.18800 & 2.23082 & 0.010 & -10.7653 & -1.6107 \\
\hline & & 2.00 & -2.01300 & 2.23082 & 0.375 & -6.5903 & 2.5643 \\
\hline \multirow[t]{6}{*}{$X-\left(^{\circ}\right)$} & \multirow[t]{2}{*}{1.00} & 2.00 & -3.68900 & 3.26252 & 0.268 & -10.3831 & 3.0051 \\
\hline & & 3.00 & -7.07000 & 3.26252 & 0.039 & -13.7641 & -.3759 \\
\hline & \multirow[t]{2}{*}{2.00} & 1.00 & 3.68900 & 3.26252 & 0.268 & -3.0051 & 10.3831 \\
\hline & & 3.00 & -3.38100 & 3.26252 & 0.309 & -10.0751 & 3.3131 \\
\hline & \multirow[t]{2}{*}{3.00} & 1.00 & 7.07000 & 3.26252 & 0.039 & .3759 & 13.7641 \\
\hline & & 2.00 & 3.38100 & 3.26252 & .309 & -3.3131 & 10.0751 \\
\hline \multirow[t]{6}{*}{$Y+\left(^{\circ}\right)$} & \multirow[t]{2}{*}{1.00} & 2.00 & 2.33300 & 2.48711 & .357 & -2.7701 & 7.4361 \\
\hline & & 3.00 & 4.98700 & 2.48711 & 0.055 & -.1161 & 10.0901 \\
\hline & \multirow[t]{2}{*}{2.00} & 1.00 & -2.33300 & 2.48711 & 0.357 & -7.4361 & 2.7701 \\
\hline & & 3.00 & 2.65400 & 2.48711 & 0.295 & -2.4491 & 7.7571 \\
\hline & \multirow[t]{2}{*}{3.00} & 1.00 & -4.98700 & 2.48711 & 0.055 & -10.0901 & .1161 \\
\hline & & 2.00 & -2.65400 & 2.48711 & 0.295 & -7.7571 & 2.4491 \\
\hline \multirow[t]{6}{*}{$Y-\left(^{\circ}\right)$} & \multirow[t]{2}{*}{1.00} & 2.00 & -5.47200 & 4.07034 & 0.190 & -13.8236 & 2.8796 \\
\hline & & 3.00 & -8.28400 & 4.07034 & 0.052 & -16.6356 & .0676 \\
\hline & \multirow[t]{2}{*}{2.00} & 1.00 & 5.47200 & 4.07034 & 0.190 & -2.8796 & 13.8236 \\
\hline & & 3.00 & -2.81200 & 4.07034 & 0.496 & -11.1636 & 5.5396 \\
\hline & \multirow[t]{2}{*}{3.00} & 1.00 & 8.28400 & 4.07034 & 0.052 & -.0676 & 16.6356 \\
\hline & & 2.00 & 2.81200 & 4.07034 & 0.496 & -5.5396 & 11.1636 \\
\hline \multirow[t]{6}{*}{$Z+\left(^{\circ}\right)$} & \multirow[t]{2}{*}{1.00} & 2.00 & 10.28330 & 5.44684 & 0.070 & -.8927 & 21.4593 \\
\hline & & 3.00 & 16.65510 & 5.44684 & 0.005 & 5.4791 & 27.8311 \\
\hline & \multirow[t]{2}{*}{2.00} & 1.00 & -10.28330 & 5.44684 & 0.070 & -21.4593 & .8927 \\
\hline & & 3.00 & 6.37180 & 5.44684 & 0.252 & -4.8042 & 17.5478 \\
\hline & 3.00 & 1.00 & -16.65510 & 5.44684 & 0.005 & -27.8311 & -5.4791 \\
\hline & & 2.00 & -6.37180 & 5.44684 & 0.252 & -17.5478 & 4.8042 \\
\hline$Z-\left({ }^{\circ}\right)$ & 1.00 & 2.00 & -8.10550 & 7.93309 & 0.316 & -24.3829 & 8.1719 \\
\hline & & 3.00 & -14.69300 & 7.93309 & 0.075 & -30.9704 & 1.5844 \\
\hline & 2.00 & 1.00 & 8.10550 & 7.93309 & 0.316 & -8.1719 & 24.3829 \\
\hline & & 3.00 & -6.58750 & 7.93309 & 0.414 & -22.8649 & 9.6899 \\
\hline & 3.00 & 1.00 & 14.69300 & 7.93309 & 0.075 & -1.5844 & 30.9704 \\
\hline & & 2.00 & 6.58750 & 7.93309 & 0.414 & -9.6899 & 22.8649 \\
\hline
\end{tabular}

maximum operating angle (in degree) in three degrees of freedom.

In the result of the variance analysis given in Table 2, the sum of the squared variance, the mean square, the $F$ value, and the probability $P$ of the groups are given. It can be seen from the significance level $P<0.05$ that there was a significant difference in the mean value between groups in the positive and negative directions of the $X$ - and $Y$-axes and the positive direction of the $Z$-axis at the 0.05 level.

Figure 10 shows the histogram of the range of the movement of the hand in the positive and negative 


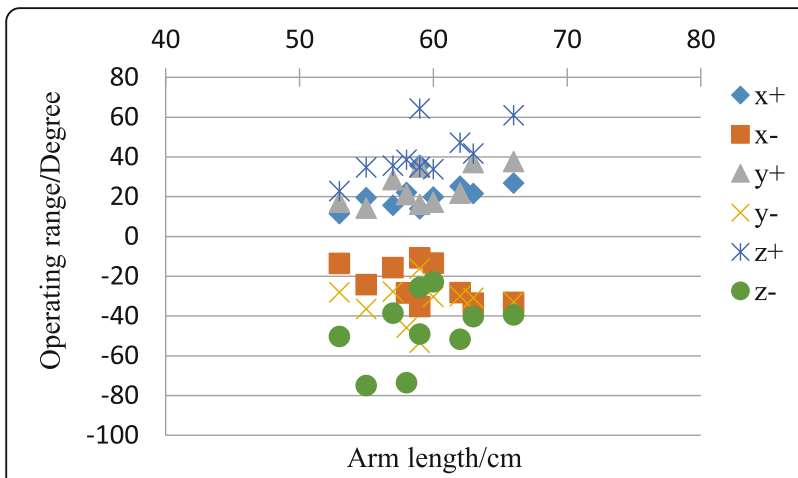

Fig. 12 The scatter plot of the relationship between the operating range and the arm length

directions of the $X, Y$, and $Z$ under the conditions of three grades of restoration force. The abscissa in Fig. 11 is 1,2 , and 3, representing the motor restoration force of $0 \mathrm{~N}, 2 \mathrm{~N}$, and $4 \mathrm{~N}$ respectively and the vertical axis represents the maximum motion range in degree $\left({ }^{\circ}\right)$.

As can be seen from Fig. 10, the restoration force has an important effect on the operating range of the haptic device in all directions. The greater the restoration force, the smaller the corresponding operating range. This is possibly because the restoration force constraints the free motion of the operator to some extent. So the restoration force should be minimized in the condition that the restoration is ensured.

\subsection{Relationship between the speed of the avatar and the operating range}

In this experiment, the speed of the virtual avatar is set at $0.5 \mathrm{~cm} / \mathrm{s}, 1.5 \mathrm{~cm} / \mathrm{s}$, and $2.5 \mathrm{~cm} / \mathrm{s}$ respectively and the other factors are set as default factors. Three groups of the operable range were recorded in degree $\left(^{\circ}\right)$ and one-way analysis of variance (ANOVA) was used to study the effects of different conditions. The results are shown in Table 3.

It can be seen from the significance level $(P<0.05)$ that the intra-group means along $X$-axis positive direction and $Z$-axis positive direction are significantly different $(P<0.05)$ while the differences in other directions are not significant. Furthermore, the differences of the measurement data were compared with the homogeneity test of variances, and the results indicated there was no significant difference between the variance of each group at the 0.05 level; that is, the variance is homogeneous, as is shown in Table 4.

Least significant difference (LSD) multiple comparison procedure was used for further analysis. In Table 5, the experimental mean values were compared while the avatar in VR moved at different speeds. When the significance level was less than 0.05 , there was a significant difference between the two groups. The results show that there is a significant difference in operating range in the six directions when the virtual object moved at the lowest speed and the highest speed, which indicates that the speed of the virtual object has an effect on the amplitude of the haptic device.

Figure 11 shows the histogram of the operating range of the haptic device in the positive and negative directions of $X, Y$, and $Z$-axis under the conditions of three grades of avatar speed. The abscissa in Fig. 12 is 1,2 , and 3 , representing the avatar speed of $0.5 \mathrm{~cm} / \mathrm{s}, 1.5 \mathrm{~cm} / \mathrm{s}$, and $2.5 \mathrm{~cm} / \mathrm{s}$ respectively. The vertical axis represents the maximum operating angle in degrees in the corresponding direction.

It can be seen from Fig. 11 that the moving speed of the virtual avatar has a certain influence on the operating range in each direction. The larger the moving speed, the smaller the operating range in the corresponding motion direction.

\subsection{Relationship between the arm length and the operating range}

In the experiment, the length of the right arm (the distance from the scapula to the palm) of each subject was measured. Figure 12 shows the scatter plot of the relationship between the operating range and the arm length. The abscissa is the arm length and the ordinate is the average operating range of multiple experiments.

Method of correlation analysis was applied to study the relevance. In this paper, the Spearman correlation coefficient was used to analyze the relationship between the arm length and the operating range. The results are shown in Table 6.

From Table 6, the operating range correlates with the arm length in the $X$-axis and $Y$-axis positive direction at the 0.05 significant level. Because the $X$-axis positive direction is to move the handle of the haptic device to right and the $Y$-axis positive direction is to move forward, it can be deduced that the operating range and the arm

Table 6 Operation space range and arm length correlation coefficient table

\begin{tabular}{|c|c|c|c|c|c|c|c|c|}
\hline & & & $X+\left({ }^{\circ}\right)$ & $X-\left({ }^{\circ}\right)$ & $Y+\left({ }^{\circ}\right)$ & $Y-\left({ }^{\circ}\right)$ & $Z+\left(^{\circ}\right)$ & $Z-\left(^{\circ}\right)$ \\
\hline \multirow{3}{*}{$\begin{array}{l}\text { Spearman rank correlation } \\
\text { coefficient }\end{array}$} & \multirow[t]{3}{*}{ Arm length $(\mathrm{cm})$} & Correlation coefficient & 0.638 & -0.413 & 0.675 & -0.122 & 0.626 & 0.371 \\
\hline & & Sig.(double sides) & 0.047 & 0.235 & 0.032 & 0.783 & 0.053 & 0.291 \\
\hline & & $N$ & 10 & 10 & 10 & 10 & 10 & 10 \\
\hline
\end{tabular}


Table 7 Operating range statistics

\begin{tabular}{|c|c|c|c|c|c|c|}
\hline & $X+\left({ }^{\circ}\right)$ & $X-\left({ }^{\circ}\right)$ & $Y+\left({ }^{\circ}\right)$ & $Y-\left({ }^{\circ}\right)$ & $Z+\left({ }^{\circ}\right)$ & $Z-\left({ }^{\circ}\right)$ \\
\hline \multicolumn{7}{|c|}{ Speed of virtual object } \\
\hline Slow & 21.709 & -24.406 & 25.479 & -33.013 & 41.948 & -47.341 \\
\hline Medium & 17.534 & -20.717 & 23.146 & -27.541 & 31.665 & -39.235 \\
\hline Fast & 15.521 & -17.336 & 20.492 & -24.729 & 25.293 & -32.648 \\
\hline \multicolumn{7}{|l|}{ Reset force } \\
\hline Small & 22.002 & -24.606 & 25.742 & -32.987 & 43.648 & -47.347 \\
\hline Fast & 16.194 & -20.453 & 18.010 & -25.108 & 27.031 & -38.595 \\
\hline Large & 15.013 & -14.405 & 16.755 & -20.160 & 27.707 & -32.169 \\
\hline
\end{tabular}

length are positively correlated when the handle is moved away from the body and the correlation coefficients are 0.638 and 0.655 respectively.

\subsection{Differences in operating range along different directions}

Table 7 shows the operating ranges of the experimenter in each direction in each experiment, i.e., the maximum operating angle.

As can be seen from Table 7 , the maximum range along $X$ and $Y$ negative direction is greater than that along the positive direction. $X$ negative direction represents moving the handle to the left and positive direction represents moving the handle to the right. Similarly, $Y$ negative direction represents moving the handle close to the operator and the positive direction represents moving the handle away from the operator. It can be concluded that the motion of the operator's handle toward himself/herself is greater than moving away from himself/herself. This means that asymmetric control interval is necessary for a haptic device-based system.

\subsection{Determination of operating range and operation speed}

Three sets of experiments were taken to study the operating range of the haptic device while the moving speed of the virtual object was controlled at the medium speed and the reset force is provided by the rubber bands. According to Table 7, we can obtain that under the above conditions the average range of hand movement is roughly $-21.96^{\circ} \sim 19.74^{\circ}$ along the $X$-axis angle, $-29.25^{\circ}$ to $24.95^{\circ}$ along the $Y$-axis and $-41.60^{\circ}$ to $39.09^{\circ}$ around the $Z$-axis.

The distance from the end of the handle to the intersection of three axes is about $30 \mathrm{~cm}$, so the magnitude of the swing from left to right is about $-11.49 \sim 10.33 \mathrm{~cm}$, the magnitude of the swing forwards or backwards is about $-15.32 \sim 13.06 \mathrm{~cm}$, and the wrist rotation angle range is $-41.60^{\circ} \sim 39.09^{\circ}$.

In the experiment, the speed at which the operator operates the handle is recorded at the same time, so the maximum operating speed of the operator can be obtained by the above method. Table 8 shows the operating speed of the subjects in each direction in experiments, in degrees per second.

Since the moving speed and the reset force of the virtual avatar have no significant effect on the operating speed, all the experimental results are averaged and the maximum operating speed in different directions can be obtained. The operating speed in the $X, Y$, and $Z$-axes is $-109.18^{\circ} /$ $\mathrm{s} \sim 98.38^{\circ} / \mathrm{s}, \quad-99.73^{\circ} / \mathrm{s} \sim 92.06^{\circ} / \mathrm{s},-310.60^{\circ} / \mathrm{s} \sim 300.75^{\circ} / \mathrm{s}$ respectively. Converted the speed to translation in the workspace, the operating speed from left to right is $-57.17 \sim 51.51 \mathrm{~cm} / \mathrm{s}$, the operating speed forwards and backwards is $-52.22 \sim 48.20 \mathrm{~cm} / \mathrm{s}$. That is, the operators are used to operating the haptic device at such speed and this should be considered while an interactive system is designed using a haptic device.

Ergonomics is actually the study of the relationship between people, machines, and the environment, aiming at safety, health, comfort, and efficiency optimization. The research content can be the study on human factors, the optimization of the human-machine system design, improvements of operations, analysis of the environment, and so on. As for the haptic

Table 8 Operation speed data statistics

\begin{tabular}{|c|c|c|c|c|c|c|}
\hline Direction & $X+(\% / s)$ & $X-(\% / s)$ & $Y+(\% / s)$ & $Y-(\% / s)$ & $Z+(\% / s)$ & $Z-(\%)$ \\
\hline \multicolumn{7}{|l|}{ Class } \\
\hline \multicolumn{7}{|c|}{ Speed of virtual object } \\
\hline Slow & 102.333 & -111.000 & 101.999 & -103.666 & 381.943 & -347.221 \\
\hline Medium & 83.333 & -113.333 & 76.333 & -100.333 & 280.555 & -305.555 \\
\hline Fast & 89.524 & -108.095 & 71.428 & -76.666 & 255.952 & -259.920 \\
\hline \multicolumn{7}{|c|}{ Reset force } \\
\hline Small & 99.333 & -101.666 & 104.332 & -101.999 & 387.499 & -348.610 \\
\hline Fast & 98.000 & -106.333 & 90.333 & -112.333 & 255.555 & -312.500 \\
\hline Large & 110.000 & -110.476 & 104.761 & -89.523 & 261.904 & -287.698 \\
\hline
\end{tabular}


interaction system, not only precise measurement and reliable force feedback but also ergonomics research is required to adapt to the operator's physiology and psychology. Ergonomic experiments and assessments are important to choose proper parameters in designing a comfort and efficient haptic device and the interaction system.

\section{Conclusions}

In this study, a 3-DOF haptic device was designed to provide three DOF force feedback to human operators. VR-based interactive system using the developed device was built and ergonomic experiments were conducted. The effective data collected by the force feedback handle system was used for statistical analysis. The characteristic efficiency and workspace were mainly analyzed. Statistical analysis was used to study the influencing factor including the guiding force, the reset force, the speed of the virtual object, and the arm length. The experimental results can provide evidence for how to design and optimize the haptic device and the haptic interactive system. Besides the factors explored in this research, human factors such as the human operator's character, proficiency, perceptual and behavior habits, and the mechanical factor such as the shape of the handle and the size of the haptic device will also influence the haptic interaction. These factors would be explored further.

\section{Abbreviations \\ DOF: Degrees of freedom; LSD: Least significant difference; MFC: Microsoft Foundation Class; OpenGL: Open Graphics Library; VR: Virtual reality}

\section{Acknowledgements}

The authors thank the editor and anonymous reviewers for their helpful comments and valuable suggestions.

\section{Funding}

This paper is supported by the National Key Research and Development Program of China (No. 2016YFB1001301), NSFC 61673114 and Shanghai Aerospace Science and Technology Innovation Fund SAST2017-021.

\section{Availability of data and materials}

We can provide the data.

\section{Authors' contributions}

All authors take part in the discussion of the work described in this paper. $\mathrm{HL}$ organized the research. AS and BL joined in the design of the haptic device and conducted calibration experiments. BX and $\mathrm{HZ}$ participated in the formulation of main design targets. This writing was finished by $\mathrm{HL}$ and supervised by AS. All authors approved the final version of this paper.

\section{Authors' information}

Hui-Jun Li received her B.S. degree in measurement and control in 1999, and M.S. degree in condensed matter physics in 2002 from Zhengzhou University, Zhengzhou, and Ph.D. degree in measurement and control from Southeast University, Nanjing, in 2005. She is currently an associate professor with the School of Instrument Science and Engineering, Southeast University, Nanjing. Her research interests are on teleoperation, space robot, and rehabilitation robot.

Ai-Guo Song received the B.S. degree in automatic control and the M.S. degree in measurement and control from the Nanjing University of Aeronautics and Astronautics, Nanjing, China, in 1990 and 1993, respectively, and the Ph.D. degree in measurement and control from Southeast University, Nanjing, China, in 1996. From 1996 to 1998, he was an Associate Researcher with the Intelligent Information Processing Laboratory, Southeast University. From 1998 to 2000, he was an Associate Professor with the Department of Instrument Science and Engineering, Southeast University. From 2000 to 2003, he was the Director of the Robot Sensor and Control Laboratory, Southeast University. From April 2003 to April 2004, he was a Visiting Scientist with the Laboratory for Intelligent Mechanical Systems, Northwestern University, Evanston, IL, USA. He is currently a Professor with the School of Instrument Science and Engineering, Southeast University. His current interests include teleoperation, haptic display, Internet telerobotics, and distributed measurement systems.

Bo-Wei Li received her B.S. degree in measurement and control in 2013 from Nanjing University of Science and Technology and M.S. degree in condensed matter physics from Southeast University, Nanjing, in 2016. She is currently an engineer engaging in the development of human-machine interface and related algorithms.

Bao-Guo Xu received his B.S. degree in measurement and control from China University of Mine and Technology, Xuzhou, China, in 2004 and Ph.D. degree in measurement and control from Southeast University, Nanjing, China, in 2009. He is currently an Associate Professor in the School of Instrument Science and Engineering, Southeast University. His interests include brain computer interface and rehabilitation robot.

Hong Zeng received the Ph.D. degree in computer science from Hong Kong Baptist University, Hong Kong, in 2010. He is currently an Associate Professor with the State Key Laboratory of Bioelectronics, Robot Sensor and Control Laboratory, School of Instrument Science and Engineering, Southeast University, Nanjing, China. His current research interests include bioRobot/ bioMechatronic interfaces, haptic interaction systems and cortically coupled human-machine collaboration.

Ethics approval and consent to participate

Not applicable.

\section{Consent for publication}

Not applicable.

\section{Competing interests}

The authors declare that they have no competing interests.

\section{Publisher's Note}

Springer Nature remains neutral with regard to jurisdictional claims in published maps and institutional affiliations.

Received: 15 July 2018 Accepted: 6 September 2018

Published online: 27 September 2018

\section{References}

1. A. Bolopion, S. Régnier, A review of haptic feedback teleoperation systems for micromanipulation and microassembly[J]. IEEE Trans. Autom. Sci. Eng. 10(3), 496-502 (2013)

2. T. Sasaki, K. Kokubo, H. Sakai, Hydraulically driven joint for a force feedback manipulator[J]. Precis. Eng. 47, 445-451 (2017)

3. C. Pacchierotti, L. Meli, F. Chinello, et al., Cutaneous haptic feedback to ensure the stability of robotic teleoperation systems[J]. Int. J. Robot Res. 34(14), 1773-1787 (2015)

4. F. Oscari, R. Oboe, O.A. Daud Albasini, et al., Design and construction of a bilateral haptic system for the remote assessment of the stiffness and range of motion of the hand[J]. Sensors 16(10), 1633 (2016)

5. Laycock S D, Day A M. Recent developments and applications of haptic devices[C], Computer Graphics Forum. Oxford: Blackwell Publishing, Inc, 2003, 22(2): 117-132.

6. D. Borro, J. Savall, A. Amundarain, et al., A large haptic device for aircraft engine maintainability [J]. IEEE Comput. Graph. Appl. 24(6), 70-74 (2004)

7. R.J. Adams, M.R. Moreyra, B. Hannaford, in Proc of the Asme Winter Annual Meeting Haptics Symposium. Excalibur, a three-Axis force display[J] (2010)

8. M.C. Çavuşoğlu, D. Feygin, F. Tendick, A critical study of the mechanical and electrical properties of the phantom haptic interface and improvements for highperformance control[J]. Presence Teleop. Virt. 11(6), 555-568 (2002)

9. Xitact Medical Simulation, http://www.xitact.com. Accessed 16 Sept 2018. 
10. M. Noakes, L. Love, P. Lloyd, Telerobotic planning and control for DOE D\&D operations (IEEE International Conference on Robotics and Automation, Washington DC, 2002), pp. 3485-3492

11. E.L. Faulring, J.E. Colgate, M.A. Peshkin, The cobotic hand controller: Design, control and performance of a novel haptic display[J]. Int. J. Robot. Res. 25(11), 1099-1119 (2006)

12. X.J. He, K.S. Choi, Safety control for impedance haptic interfaces[J]. Multimed. Tools Appl. 75(23), 15795-15819 (2016)

13. Sun X, Andersson K, Sellgren U, Towards a Methodology for Multidisciplinary Design Optimization, Proceedings of the ASME 2015 International Design Engineering Technical Conferences \& Computers and Information in Engineering Conference IDETC/CIE 2015, Boston, Massachusetts, USA; 2015.

14. H. Qin, A. Song, Y. Liu, et al., Design and calibration of a new 6 DOF haptic device[J]. Sensors 15(12), 31293-31313 (2015)

15. B. Sauvet, T. Laliberte, C. Gosselin, Design, analysis and experimental validation of an ungrounded haptic interface using a piezoelectric actuator[]]. Mechatronics 45, 100-109 (2017)

16. I. Sarakoglou, N. Garcia-Hernandez, N.G. Tsagarakis, et al., A high performance tactile feedback display and its integration in teleoperation[J]. IEEE Trans. Haptics 5(3), 252-263 (2012)

17. X. Sun, U. Sellgren, K. Andersson, Situated design optimization of haptic devices[J]. Procedia CIRP 50, 293-298 (2016)

18. H.Z. Tan, M.A. Srinivasan, B. Eberman, et al., Human factors for the design of force-reflecting haptic interfaces[]]. Dyn. Syst. Control 55(1), 353-359 (1994)

19. R. Ellis, O. Ismaeil, M. Lipsett, Design and evaluation of a high-performance haptic interface. Robotica 14, 321-327 (1996)

20. Yoon W K, Suehiro T, Tsumaki Y, et al. A method for analyzing parallel mechanism stiffness including elastic deformations in the structure[C] Intelligent Robots and Systems, 2002. IEEE/RSJ International Conference on. IEEE, 2002(34):633-634

\section{Submit your manuscript to a SpringerOpen ${ }^{\circ}$ journal and benefit from:}

- Convenient online submission

- Rigorous peer review

- Open access: articles freely available online

- High visibility within the field

- Retaining the copyright to your article

Submit your next manuscript at $\boldsymbol{\nabla}$ springeropen.com 